
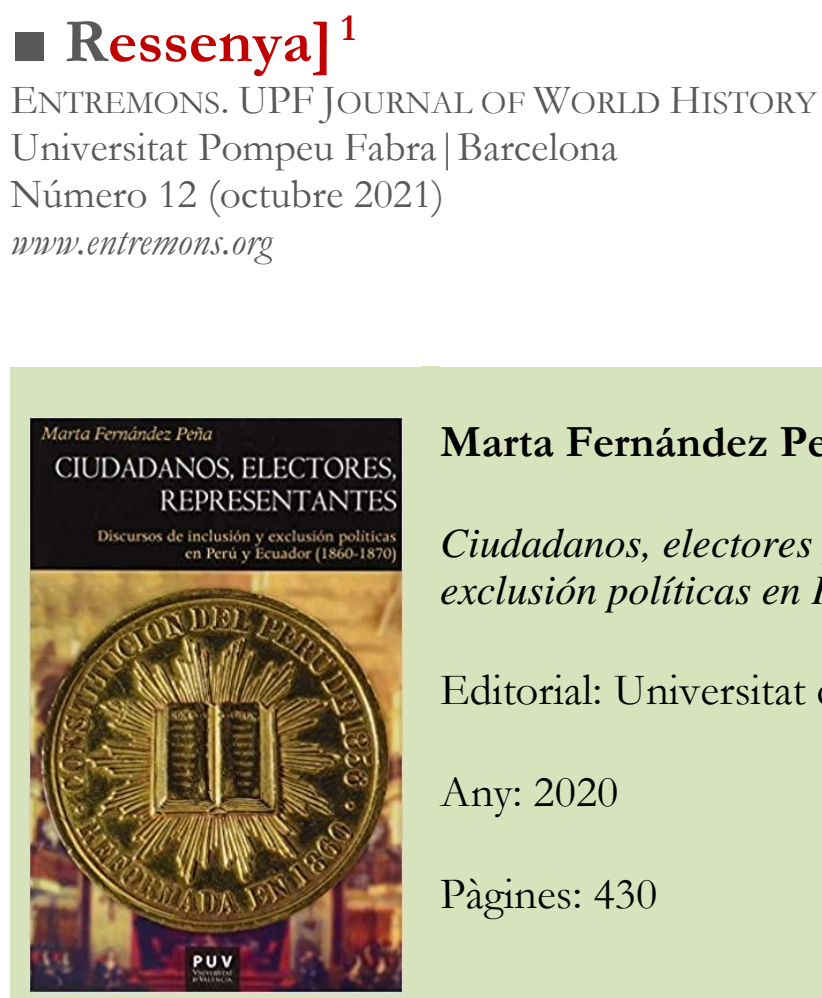

\title{
Marta Fernández Peña
}

Ciudadanos, electores y representantes. Discursos de inclusión y exclusión políticas en Perú y Ecuador (1860-1870).

Editorial: Universitat de València

Any: 2020

Pàgines: 430

\section{Miguel Adolfo Galindo Pérez \\ migueladog11@zedat.fu-berlin.de}

Este libro de Marta Fernández Peña es un trabajo enriquecedor que se ocupa de la configuración y definición de la ciudadanía y el electorado como conceptos activos en el desarrollo práctico y discursivo de la política electoral de Ecuador y Perú en la década de 1860. Periodo en el que el sistema representativo de ambos países pasaba por una etapa de consolidación y desarrollo, debido a la convergencia entre la consolidación de las teorías liberales europeas y americanas del siglo XVIII y XIX; y la introducción de postulados sobre la libertad, la igualdad y la nación. Partiendo de un marco espacio temporal fijo y una estructura fundada en criterios temáticos y no cronológicos, realiza un diagnóstico de las similitudes y diferencias más significativas que produjo el desarrollo del liberalismo como cultura política y sus manifestaciones vernáculas, a partir del cual la idea de "ciudadano" y "elector" se relacionaron intrínsecamente con los criterios de inclusión y exclusión en cada modelo electoral.

\footnotetext{
${ }^{1}$ DOI: $10.31009 /$ entremons.2021.i12.04
} 
Aprovechando los elementos comunes existentes entre ambas naciones -comprendidas como similitudes étnicas, económicas, sociales y políticas- establece analogías sobre los imaginarios creados por la cultura legal de ambos países, encargadas de fomentar las líneas de restricción en el juego político. En mis notas de lectura de Ciudadanos, electores $y$ representantes es constante encontrar observaciones sobre las relaciones de poder identitarias reconocibles en la misma desconexión, llamémoslo un divorcio social, entre las élites nacionales y la masa de la población andina, característicamente compuesta por una comunidad cultural y étnicamente heterogénea. En este sentido el libro examina esta problemática a través de una extensa revisión documental legislativa, y el análisis la progresión discursiva de los agentes parlamentarios como actores históricos definidores de derechos y roles político-sociales de las poblaciones. En este sentido, la autora teje una serie de elementos comparativos con los cuales establece la consolidación del sistema representativo liberal andino liderado por elementos conservadores, entre los cuales se pueden encontrar criterios económicos, políticos, culturales y raciales.

Al acercarse a este tejido, el libro complejiza sobre la importancia de reconocer la conjunción entre categorías raciales y económicas en el modelo político liberal andino, desde las conexiones entre el mercado internacional del guano y el cacao en el posicionamiento de las élites financieras en Ecuador y Perú, respectivamente, en las redes comerciales internacionales. En el libro este relato es esencial para comprender el esquema jerárquico de los dos países, conformado por élites blancas burguesas con cierto nivel de instrucción, encargadas de introducir las ideas políticas liberales, dada su capacidad de acceso a la filosofía política de un espectro llamado "Europa", frente a una población indígena en su mayoría analfabeta y dedicada a actividades agrícolas, habitante de un "mundo arcaico" (p. 46). En este sentido el libro ata estas características para observar cómo, pese a que las designadas nuevas altas dignidades del sistema políticoeconómico se erigieron como defensoras y precursoras de la "modernidad" el "progreso" y la "democracia", las diferencias dialécticas entre rico y robre; campo y ciudad; blanco, mestizo, indígena y afrodescendiente, continuaron siendo claves en la configuración del panorama socioeconómico.

Teniendo en cuenta que el libro parte de la intención de analizar las legislaciones electorales y los cuerpos constitucionales de los dos países andinos, el lector se encontrará con un trabajo que avanza más allá de la lectura exegética de un cuerpo legal. Por el 
contrario, uno de los aspectos de mayor interés es la reflexión sobre los debates, las interpretaciones y las reelaboraciones discursivas con las que elementos conservadores diseñaron un proyecto político de nación a partir de la base teórica del liberalismo. El impacto del relato se encuentra cuando, desde estos debates, Marta Fernández Peña se pregunta sobre los principios básicos de los sistemas representativos, que ocupan la segunda parte de su libro, pero que, contrario a lo que se podría considerar, estos principios en lugar de posicionarse como garantes básicos de acceso a las instituciones democráticas, se privilegiaron como factores restrictivos del ejercicio electoral. En síntesis, revisa cómo principios como el de libertad o igualdad fueron sometidos a una serie de imposiciones que impedían su completo ejercicio y una aplicabilidad Erga Omnes. En consecuencia, la igualdad jurídica no implicaba una igualdad política ni social, y por ende tampoco de representatividad, lo que mantuvo la desigualdad en el acceso a los derechos políticos, algo que caracterizó los sistemas políticos de la época de los dos países andinos durante el siglo XIX. Sobre esta situación el libro interpela la existencia presunta y tácita de una desigualdad entre individuos, representable en el orden jerárquico y social, formulando un determinismo selectivo y excluyente.

A partir de allí la autora establece una discusión necesaria sobre la aparición de diferentes categorías jurídico-políticas que determinaron la cultura política y el ejercicio de derechos por parte de los individuos. Este es un punto de alta elaboración en este trabajo, donde se estudia cómo la ciudadanía es entonces diseñada en constituciones y leyes electorales, desde las cuales se puede definir la idea de "elector" y "representante". El libro en consecuencia plantea una revisión de la ciudadanía desde la nacionalidad, mayoría de edad, el ejercicio de un oficio o arte útil, el estado civil, la garantía de dominio de una propiedad raíz y la capacidad de leer y escribir. En este sentido, es interesante observar cómo destaca la fuerte presencia de la religión católica tanto en la vida privada como en la pública, y su influencia en el desarrollo político de la segunda mitad del siglo XIX, reconociendo esta institución como elemento medular de la identidad nacional peruana y ecuatoriana de la época, dada la exigencia de profesar la religión católica para obtener el derecho de ciudadanía.

Con estas discusiones como trasfondo, es notable cómo el libro mantiene un ejercicio conceptual de gran alcance teórico e histórico al referirse a las otredades del sistema político preguntándose por ¿quiénes eran? ¿cómo se les excluyó? ¿cómo se construyeron las categorías de exclusión? La lista es extensa, y para cualquier conocedor de historia 
social latinoamericana es apenas laborioso adivinar quiénes la integraron. Desarraigados, dependientes, nómadas, migrantes, y en general todo aquel sujeto pernicioso que cause rechazo o sobre el que pueda caer la más mínima sospecha; asociables con la vagancia y la delincuencia dibujada en torno a las diferencias de raza, idioma religión y costumbres. Sin embargo, la autora en lugar de hacer una especulación argumentativa, y sin caer en terrenos comunes, problematiza en torno a las discusiones parlamentarias sobre la libertad de cultos, que encontró su periodo coyuntural durante la década de 1860 en ambos países, y que tuvo un impacto importante en las capas sociales indígenas, a los inmigrantes no católicos -"paganos" (p. 289)- excluidos del debate político por profesar "falsos cultos" al interior de dos estados confesionales.

A mi juicio, uno de los puntos de mayor impacto que tiene el texto se encuentra al elaborar la historia de las subalternidades en la vida privada, y su relación con el acceso al sufragio. Allí se condensan lo dicho y lo no dicho, lo escrito y la episteme, las fuentes parlamentarias y las reglas del saber constituidas como dispositivos discursivos de $-\mathrm{y}$ dentro de- la familia, el hogar y las relaciones personales. Con esto me refiero al análisis que realiza Marta Fernández Peña sobre aquellos considerados incapaces de tomar sus propias decisiones por estar sometidos a un "individuo superior" (p. 293). Dependencia entendida en términos económicos, profesionales, jurídicos o políticos, y que son representados por una inferioridad intelectual, profesional y de género. Entre ellos: mendigos, sirvientes domésticos, esclavos, militares de rango bajo e incluso mujeres. Es de gran interés cómo el libro aborda las construcciones legales y culturales con las que se constituyó el rol sociopolítico de la mujer. La autora resalta con precisión cómo la construcción cultural de la dependencia de la mujer en términos jurídicos económicos y sociales, se veía comprometido en el ámbito político, en el que el voto del hombre comprendía el de su esposa y su familia, limitando y excluyendo la participación política de la mujer. El sistema liberal ecuatoriano y peruano trasladó la regulación de la vida privada al ejercicio de derechos políticos en la esfera pública llegando a argumentarse en el Código Civil peruano de 1852 (vigente hasta 1936) que "bajo la palabra del hombre se comprende la mujer" (p. 295).

Me parece importante recomendar el libro de Marta Fernández Peña, esta investigación fruto de su tesis doctoral en la Universidad de Sevilla es un trabajo bien escrito, rico en material empírico, novedoso y riguroso, que invita a comprender cómo el liberalismo andino se mantiene dentro de una constante tensión entre la integración y asimilación de 
los habitantes de sus territorios, frente a la exclusión de comunidades consideradas un lastre en el proceso de construcción de un proyecto político de nación "homogénea y civilizada" (p. 314). Además, es un texto que atiende a los detalles de las transferencias culturales e influencias ideológicas entre Europa y América Latina sin valorarlos en términos de "centro" y "periferia". Estudia cómo los sistemas representativos no se constituyeron de forma aislada, sino por su inmersión dentro de un marco espacial amplio de teorías filosóficas, modas intelectuales, sistemas institucionales y actores que se movían por el espacio atlántico. El libro identifica apropiadamente cómo las ideas introducidas fueron reinterpretadas, reelaboradas y adaptadas a sus propias circunstancias internas.

Finalmente, Marta Fernández Peña nos invita a reflexionar sobre cómo las construcciones sociales y políticas del siglo XIX ha sido fundamento para la elaboración y consolidación de los sistemas políticos electorales actuales. Sin dudas, los historiadores comprendemos la problemática que implica comparar el pasado con el presente, por el peso mismo de cada contexto y el riesgo de caer en anacronismos. Sin embargo, en su análisis la autora empuja a señalar continuidades y cambios, abrazando la posibilidad de tomar postura sin renunciar al estudio riguroso de la historia política y social. Por ende, el libro invita a comprender las tesis del liberalismo decimonónico como una herramienta para poder acercarnos a las concepciones actuales sobre ciudadanía, representación, participación política y sus líneas de inclusión y exclusión. 